\title{
DETERMINATION OF ILLNESS COGNITION LEVELS IN PATIENTS WITH MAXILLOFACIAL AREA DEFECTS
}

\author{
Lamia Najafova $^{1}$, Hilal Eksi Ozsoy ${ }^{2 *}$, Huseyin Kurtulmus ${ }^{3}$ \\ ${ }^{1}$ Department of Prosthodontics, Faculty of Dentistry, Istanbul Aydin University, Turkey \\ ${ }^{2}$ Faculty of Dentistry, Beykent University, Turkey \\ ${ }^{3}$ Department of Prosthodontics, Faculty of Dentistry, Beykent University, Turkey \\ *Correspondence email : hilaleksi@gmail.com
}

\begin{abstract}
The aim of this study was to measure the illness cognition of patients with defect in the maxillofacial region. Eighty patients participated in this study. Written informed consent was obtained from patients with maxillofacial area defect, and the patients were filled in with the guidance of the researchers. Illness Cognition Questionnaire (ICQ), forms measuring the illness awareness of the patients were completed. The study was conducted independently of demographic characteristics. The statistical software SPSS (Statistical Package for Social Sciences, Version 20, Chicago IL, USA) was used for calculations. At the end of the study, ICQ scores in patients with maxillofacial defect were as follows: There was a statistically significant intra class correlation of $88.6 \%(0.843-0.942)$ among the Helplessness scale scores of the participants. There was a statistically significant intra class correlation of $80.3 \%(0.728-0.863)$ among the Acceptance scale scores of the participants. There was a statistically significant intra class correlation of $0.752 \%(0,657-0,827)$ among the Perceived benefits scale scores of the participants. Patients with maxillofacial defects will focus on the disease cognition "Helplessness" category. In patients with relationship maxillofacial defect, the rate of helplessness $(88.6 \%)$ was higher than acceptance $(80.3 \%)$ and perceived benefit $(0,752 \%)$.
\end{abstract}

Keywords: ICQ; Facial Defect; SPSS

\section{INTRODUCTION}

Recently, it is of almost importance that patients are notified to physicians about this process in order to monitor the progress of the disease and provide better quality service to patients. Deformity in the maxillofacial region caused by some reasons can have devastating effects on the aesthetic, functional, economic and psychosocial aspects of patients' lives. ${ }^{1}$

Anatomical changes in orofacial area, which occurs after surgery and treatment for orofacial cancer or trauma, can lead to different dysfunction in mouth such as changes and difficulties in swallowing, speech and chewing. ${ }^{2}$
For many people, who cancer survive and have maxillofacial deformity, psychological distress are a common ailment. ${ }^{3}$ The study has shown, that $25 \%$ of patient with maxillofacial cancer and who was undergoing radiation treatment, are in psychological distress symptoms. ${ }^{4}$

Individuals' perspective on the events affects the disease progression. The cultural capacity of the patients is one of the important factors in the progression of the disease. Assessment of patients' cognitive status is one of the most important factors for understanding, controlling and treating stress and psychiatric disorders. ${ }^{5}$

Evers et al. developed the Illness Cognition Questionnaire (ICQ), which 
measures the level of cognition of illness in individuals suffering from the disease. ${ }^{6}$ The advantages of this study cognition questionnaire are: cost-effectiveness, validity and reliability, ease of application. This questionnaire expresses the opinions of patients who have suffered from the disease for a long time. Many studies show that patients with a defect in the maxillofacial area undergo psychological change. ${ }^{7,8}$

\section{MATERIAL AND METHODS}

This research was conducted in Departments of Prosthodontics in Istanbul Aydın University, Faculty of Dentistry. Eighty patients with maxillofacial defects admitted to the prosthetic dentistry were included in the study. Demographic characteristics were not taken into consideration in the study. A total of 80 patients with facial defects were asked a questionnaire. The ethical form for this research was given by the Ethics Committee of İstanbul Aydın University. Written consent was obtained from the individuals included in the study and ICQ forms measuring the disease awareness of the patients were completed. The research was based on the Helsinki Declaration. ICQ, which measures the disease awareness level of patients suffering from chronic illness, is a scale consisting of 18 questions. 18 questions are divided into 3 separate subcategories. Each category contains 6 questions. Subcategories are disease acceptance, helplessness, and perceived benefits. As an example: 'acceptance of the disease' is the positive perception of the negativity of the individual: "I learned to live with the partial loss of my orofacial after illness". The explanation of 'helplessness' - the negative consequences that the disease brings to the daily life of individuals: "It limits me to everything that is important in my life because of defects in my face due to illness ". The explanation of perceived benefits is that patients who experience loss in the maxillofacial region can benefit: "After the loss of my face, I learned to enjoy the moment in life."

\section{RESULTS}

The statistical software SPSS (Statistical Package for Social Sciences, Version 20, Chicago IL, USA) was used for calculations. All values presented as mean \pm standard deviation and mean (Maximum- Minimum) percent and frequencies (Table 1). The results of the homogeneity (Levene's Test) and normality tests (Shapiro Wilk) were used to decide which statistical methods to apply in the comparison of the study groups. The relationship between the two continuous variables was evaluated by the Pearson Correlation Coefficient and Spearman Correlation Coefficient when the parametric test did not meet the prerequisites. Test-retest reliability coefficients were evaluated by intraclass correlation coefficient. $p$ values $<0.05$ were considered statistically significant

Table 1. Descriptive statistics

\begin{tabular}{cccccc}
\hline & $\mathrm{N}$ & Min & Maximum & Mean & Standard Deviation \\
\hline Helplessness-M & 80 & 6.00 & 24.00 & 14.4750 & 4.66328 \\
\hline Acceptance-M & 80 & 6.00 & 24.00 & 15.4625 & 5.50246 \\
\hline Perceived_benefits-M & 80 & 6.00 & 24.00 & 18.7625 & 4.88667 \\
\hline
\end{tabular}


There was a statistically significant intra class correlation of $88.6 \%(0.843-$ 0.920 ) among the Helplessness scale scores of the participants. There was a statistically significant intra class correlation of $80.3 \%$ (0.728-0.863) among the Acceptance scale

Table 2. Intraclass correlation tables

There is a statistically significant difference between "Acceptance" and "Helplessness". There is a $41.3 \%$ relationship, while one increases and the other decreases. There is a statistically scores of the participants. There was a statistically significant intra class correlation of $0.752 \% \quad(0,657-0,827)$ among the Perceived benefits scale scores of the participants (Table 2).

Table 3. Correlation tables

\begin{tabular}{c|c|c|c}
\hline & & Helplessness & Acceptance \\
\hline \multirow{3}{*}{ Acceptance } & $\mathrm{r}$ & $-0.413^{*}$ & \\
\cline { 2 - 4 } & $\mathrm{p}$ & 0,000 & \\
\cline { 2 - 4 } & $\mathrm{n}$ & 80 & $0.796^{*}$ \\
\hline \multirow{3}{*}{ Perceived_benefits } & $\mathrm{r}$ & -0.219 & 0.000 \\
\cline { 2 - 4 } & $\mathrm{p}$ & 0.051 & 80 \\
\cline { 2 - 4 } & $\mathrm{n}$ & 80 & \\
\hline
\end{tabular}

$* \mathrm{p}<0,05$

\section{DISCUSSION}

The facial structure and attractiveness of individuals affect people's reactions and judgments in society. Unattractive people are considered more negative than attractive ones. ${ }^{9}$ People, who have maxillofacial defects, can be considered a severe social disability. ${ }^{7}$

The change in the maxillofacial region due to trauma or cancer affects the individual and his/her adaptation negatively. There are very few centers that significant difference between "Perceived benefits" and "Acceptance". There is a $79.6 \%$ relationship, while one increases and the other increases (Table 3). 
opinion, since the defect affects the most visible part of the human body, the disruption of the integrity of the external appearance with the disease keeps these rates high.

The maxillofacial prosthesis treatment option; congenital orofacial deformities such as cleft palate-lip, hereditary orofacial deformities, orofacial deformities caused by tumor resection and orofacial deformities caused by trauma has been used frequently. These patients generally have a comprehensive history of their treatment and have impaired psychology due to emotional disadvantages - problems, problems-difficulties that can not be ignored. ${ }^{12}$ A person who becomes deformed suffers from loss of normality. A person affected from maxillofacial defects; strives throughout its development to ensure self-respect. Delays the development of satisfactory self image and affects the process of individuality. They can not develop feelings of valency and competence and react to individuals in terms of stamping patterns. A person is forced to regulate his or her integration into a society. In this study, it was a statistically significant difference between " Acceptance " and " Helplessness". There is a $41.3 \%$ relationship, while one increases and the other decreases. There is a statistically significant difference between "Perceived benefits" and "Acceptance". There is a $79.6 \%$ relationship, while one increases and the other increases.

Quality of life and psychological in facial rehabilitation has been extensively investigated. However, prospective studies linking the psychological quality of the individual with scales and / or emotional states are lacking. Any change in our body creates a temporary or permanent discomfort in the emotional state of our integrity. In our study, the lowest rate was the benefit of the disease causing this deformity in patients with maxillofacial defects $-0.752 \%(0.657-0.827)$.

\section{CONCLUSION}

Within the limitations of this study, the following conclusions were reached:

1. Patients with maxillofacial defects will focus on the disease cognition "Helplessness" category, the rate of helplessness $(88.6 \%)$ was higher than acceptance (80.3\%) and perceived benefit $(0.752 \%)$.

2. In patients with a maxillofacial defect relationship, if we can direct the level of cognition of illness to the category of "perceived benefit", treatments and recovery processes can be more successful.

\section{REFERENCES}

1. Atay A, Peker K, Günay Y, Ebrinç S, Karayazgan B, Uysal Ö. Assessment of health-related quality of life in Turkish patients with facial prostheses. Health Qual Life Outcomes. 2013;11(1):1-9.

2. Denaro N, Merlano MC, Russi EG. Dysphagia in head and neck cancer patients: Pretreatment evaluation, predictive factors, and assessment during radio-chemotherapy, recommendations. Clin Exp Otorhinolaryngol. 2013;6(3):117-26.

3. Shetty V, Glynn S, Brown KE. Psychosocial sequelae and correlates of orofacial injury. Dent Clin North Am. 2003;47(1):141-57.

4. Shone GR. An audit into the incidence of handicap after unilateral radical neck dissection. J Laryngol Otol. 1991;105(9):760-2.

5. Aytar A, Aykul A, Altintas A, Tigli AA. Reliability and Validity of the Turkish Version of Illness Cognition Questionnaire. Exp Aging Res. 2019;45(5):424-35.

6. Sint Nicolaas SM, Schepers SA, van den Bergh EMM, Evers AWM, Hoogerbrugge PM, Grootenhuis MA, et al. Illness cognitions and family adjustment: psychometric properties of the Illness Cognition Questionnaire for 
parents of a child with cancer. Support Care Cancer. 2016;24(2):529-37.

7. Schoen PJ, Raghoebar GM, Van Oort $\mathrm{RP}$, Reintsema $\mathrm{H}$, Van Der Laan BFAM, Burlage FR, et al. Treatment outcome of bone-anchored craniofacial prostheses after tumor surgery. Cancer. 2001;92(12):3045-50.

8. Yukawa H, Noguchi H, Nakase I, Miyamoto Y, Oishi K, Hamajima N, et al. Transduction of Cell-Penetrating Peptides Into Induced Pluripotent Stem Cells. Cell Transplant [Internet]. 2010 Jun 1 [cited 2017 Jun 6];19(6):901-9. Available from: http://www. ncbi.nlm.nih.gov/pubmed/20587149

9. Maner JK, Kenrick DT, Becker DV, Delton AW, Hofer B, Wilbur CJ, et al. Sexually Selective Cognition Beauty Captures the Mind of the Beholder. Vol. 85, Journal of Personality and Social Psychology. Maner, Jon K.: Department of Psychology, Florida State University, One University Way, Tallahassee, FL, US, 32306-1270, maner@psy.fsu.edu: American Psychological Association; 2003. p. 1107-20.

10. Lento J, Glynn S, Shetty V, Asarnow J, Wang J, Belin TR. Psychologic functioning and needs of indigent patients with facial injury: A prospective controlled study. J Oral Maxillofac Surg. 2004;62(8):925-32.

11. Burt $\mathrm{B}$ a, Eklund $\mathrm{S}$ a. J.1532849X.2000.113_3.X. 2011;9(2):1-4.

12. Baile WF, Gibertini M, Scott L, Endicott J. Depression and tumor stage in cancer of the head and neck. PsychoOncology. 1992;1(1):15-24. 